\title{
Progressive myopia in early onset chronic angle closure glaucoma
}

\author{
Mark Cherny, Anne M V Brooks, W E Gillies
}

\begin{abstract}
A 19-year-old girl presented with advanced unilateral chronic angle closure glaucoma and myopia with gross cupping and field loss in a previously hyperopic eye with a marked increase in corneal curvature. This emphasises that a marked myopic shift may be an important sign of glaucoma in a young patient. (BrF Ophthalmol 1992; 76: 758-759)
\end{abstract}

The possibility of missing a case of glaucoma which has caused the onset of myopia in a young patient is present in the minds of most ophthalmologists but usually it remains only a possibility and one seldom sees a case in clinical practice.

Recently, however, a case of unilateral chronic angle closure glaucoma (CACG) presented with unilateral high myopia with some interesting features and documentation.

\section{Case report}

A Caucasian female, presented aged 8 years. Uncorrected vision was right $6 / 12$, left $6 / 18$; refraction under mydriatic was right $+3 \cdot 0 /-1 \cdot 0$ $\times 180^{\circ}$ and left $+5 \cdot 5 /-2 \cdot 0 \times 30^{\circ}$ and the eyes were otherwise normal. At a final subjective test vision was equal, $6 / 9$, with right $+1 \cdot 0 /-1 \cdot 0$ $\times 180^{\circ}$ and left $-1.5 \times 30^{\circ}$.

She returned, age 19 years, complaining of difficulty with some recent spectacles. She stated that she had obtained the glasses from an optometrist in the period since her last visit 11 years earlier and no further information was available regarding this period. Vision was now right $6 / 12$ with $-6 \cdot 0 / 3.0 \times 60^{\circ}$ and left $6 / 9$ with $-1.0 \times 150^{\circ}$. The anterior chamber depths were rather shallow, $2.4 \mathrm{~mm}$ right and left. There was no iridodonesis. The optic cup-disc ratios were right 0.8 with atrophy, left $0 \cdot 4$. The right visual field showed a large superior arcuate loss with Goldmann 2/IV, the left was full. Applanation pressures were right 38 , left $20 \mathrm{~mm} \mathrm{Hg}$. The right angle was narrow with bowed iris and $50-90 \%$ closure by intermittent segments of peripheral anterior synechiae (PAS). The left angle was wide and open with moderate bowing of the iris and narrowed above. After bilateral YAG laser iridotomies the right angle was still closed above and intermittently elsewhere with $50-80 \%$ PAS. On pilocarpine hydrochloride and timolol maleate the IOP was right 25 , left $12 \mathrm{~mm} \mathrm{Hg}$. After an uneventful right trabeculectomy IOP was right 8 , left $12 \mathrm{~mm} \mathrm{Hg}$ with a good drainage bleb. There was no change in anterior chamber depth or lens position following the instillation of pilocarpine.

On ultrasonography the anteroposterior lengths were right $21 \cdot 1$, left $20 \cdot 7 \mathrm{~mm}$ with a normal lens thickness of $4 \cdot 1 \mathrm{~mm}$ right and left. The posterior pole of the lens was $14.0 \mathrm{~mm}$ in front of the retina in the right eye and in the left eye the posterior pole of the lens was $13.6 \mathrm{~mm}$ in front of the retina. Corneal diameters were $12 \cdot 0$ $\mathrm{mm}$ right and left. Keratometric readings were right $54 \cdot 0 / 51 \cdot 5$ axis $105^{\circ}$, left $45 \cdot 5 / 49 \cdot 1$ axis $90^{\circ}$.

The patient was of normal height and build being $160 \mathrm{~cm}(5 \mathrm{ft} 3$ ins $)$ tall with no brachydactyly.

\section{Discussion}

Angle closure glaucoma in myopia has been documented ${ }^{1}$ with an incidence from $5 \cdot 5 \%$ to $16.4 \%{ }^{2-4}$ and, though CACG is unusual in such a young patient, a number of cases have been reported..$^{5-9}$ The myopic shift in refraction in the right eye of the present case bears a marked similarity to the excessive loss of hyperopia in four young aphakic patients developing glaucoma described by Egbert and Kushner ${ }^{10}$ who could not determine whether glaucoma or myopia was the primary process. In our patient unilateral myopia occurred in a previously known hyperopic eye with the development of CACG making it highly likely that the excessive myopic shift in refraction was secondary to the pressure rise.

The axial lengths of both eyes were short and almost equal in this patient so that the myopic shift in refraction in the affected eye was not due to the lengthening of the globe typical of high myopia. Further, though greater than expected for her age, "lens thickness was equal in each eye so that the unilateral myopia was unlikely to be lenticular in origin. An anterior shift of the lens in the right eye would explain the myopic shift if it were of sufficient magnitude. However the posterior pole of the lens in the right eye was only $0.4 \mathrm{~mm}$ more anterior to the retina than that of the left eye and would not explain a myopic shift of 6 dioptres.

The high keratometry readings (more than 2 standard deviations from the mean), ${ }^{12}$ much higher in the more affected eye, indicated, therefore, that the increased refractive power was most likely to be corneal in origin, with a very highly curved cornea particularly in the right eye. It is noteworthy that this remarkable change in corneal curvature occurred though corneal diameters remained equal.

The glaucoma in this patient had some similarity to that which has been described in the Weill-Marchesani syndrome ${ }^{1314}$ with slight anterior dislocation of the lens and blockage of pupillary aqueous flow. ${ }^{15}{ }^{16}$ However this patient showed none of the physical features of the Weill-Marchesani syndrome, being of normal height and build, nor was there evidence of 
microspherophakia or dislocation of the lens into the anterior chamber.

The adolescent onset of CACG presenting with high myopia emphasises that an excessive myopic shift in refraction may occasionally be an important sign of the onset of glaucoma in a young patient.

In this patient an early onset of CACG at some time between 8 and 19 years was associated with a rise in IOP, an increase in corneal curvature in the affected eye and cupping and field loss. These changes were not accompanied by stretching of the sclera and lengthening of the globe. In the absence of any other likely explanation it seems probable that the raised IOP caused this sequence of events.

This work was carried out under Research Projects 20 and 101 of the Royal Victorian Eye and Ear Hospital.

1 Hagan JC, Lederer CM. Primary angle closure glaucoma in a myopic kinship. Arch Ophthalmol 1985; 103: 363-5.

2 Posner A, Schlossman A. The clinical course of glaucoma. A review of 474 cases from private practice. Am $\mathcal{F}$ Ophthalmol 1948; 31: 915-34.
3 Davenport RC. Facets of glaucoma. Trans Ophthalmol Soc UK 1959; 79: 3-14.

4 Lowe RF. Aetiology of the anatomical basis for the primary angle closure glaucoma. Brf Ophthalmol 1970; 54: 161-9. angle closure glaucoma. Brf Ophthalmol 1970; $54: 161-9$. . Sugar HS. Acute glaucomal
mol $1947 ; 30: 451-68$

6 Boase AJ. Acute glaucoma in an adolescent. Am $\mathcal{F}$ Ophthalmol

1948; 31: 997-9.
7 Jones DEP, Watson DM. Angle-closure glaucoma precipitated by the use of phospholine iodide for esotropia in a child. $\mathrm{BrF}$ Ophthalmol 1967; 51: 783-5.

8 Appleby RS, Kinder RSL. Bilateral angle-closure glaucoma in a 14-year-old boy. Arch Ophthalmol 1971; 86: 449-50.

9 Hallett $M$. Acute angle closure glaucoma in a young Negro boy. FAMA 1971; 215: 293-4.

10 Egbert JA, Kushner BJ. Excessive loss of hyperopia. Arch Ophthalmol 1990; 108: 1257-9.

11 Jansson F. Measurement of intraocular distances by ultrasound and comparison between optical and ultrasonic determinations of the depth of the anterior chamber. Acta Ophthalmol $(\mathrm{Kbl})$ 1963; 41: 25-61.

12 Gordon KA, Donzis PB. Ketractive development of the human Gordon KA, Donzis PB. Retractive developm

13 Weill G. Ectopie des cristallins et malformations générales. Ann Oculist (Paris) 1932; 169: 21-44.

14 Marchesani O. Brachydaktylie und angeborene Kugellinse als Systemerkrankung. Klin Monatsbl Augenheilkd 1939; 103: 392-406.

15 Jensen AD, Cross HE. Ocular complications in the WeillMarchesani syndrome. Am $\mathcal{F}$ Ophthalmol 1974; 77: 261269.

16 Willi M, Kut L, Cotlier E. Pupillary-block glaucoma in the Marchesani syndrome. Arch Ophthalmol 1973; 90: 504-8. 